\title{
Continuous neurophatic orofacial pain: A retrospective study of 23 cases
}

\author{
Dídac Sotorra-Figuerola ${ }^{1}$, Alba Sánchez-Torres ${ }^{2}$, Eduard Valmaseda-Castellón ${ }^{3}$, Cosme Gay-Escoda ${ }^{4}$
}

${ }^{1}$ DDS. Student of Oral Surgery and Implantology Department. School of Dentistry, University of Barcelona. Barcelona, Spain ${ }^{2}$ DDS. Student of Oral Surgery and Implantology Department. School of Dentistry, University of Barcelona. Barcelona, Spain ${ }^{3}$ DDS, MS, PhD, EBOS. Professor of Oral Surgery. Professor of Master of Oral Surgery and Implantology, School of Dentistry, University of Barcelona; Researcher of the IDIBELL Institute. Barcelona, Spain

${ }^{4}$ MD, DDS, MS, PhD, EBOS. Chairman and Full Professor of Oral and Maxillofacial Surgery. Director of the Master of Oral Surgery and Implantology, School of Dentistry, University of Barcelona; Researcher/Coordinator of the IDIBELL Institute; Head of Oral and Maxillofacial Surgery Department of the Teknon Medical Center. Barcelona, Spain

Correspondence:

Centre Mèdic Teknon

C/ Vilana 12

08022 - Barcelona

cgay@ub.edu

\begin{abstract}
Sotorra-Figuerola D, Sánchez-Torres A, Valmaseda-Castellón E, GayEscoda C. Continuous neurophatic orofacial pain:A retrospective study of 23 cases. J Clin Exp Dent. 2016;8(2):e153-9. http://www.medicinaoral.com/odo/volumenes/v8i2/jcedv8i2p153.pdf
\end{abstract}

Received: 03/05/2015

Accepted: 09/12/201

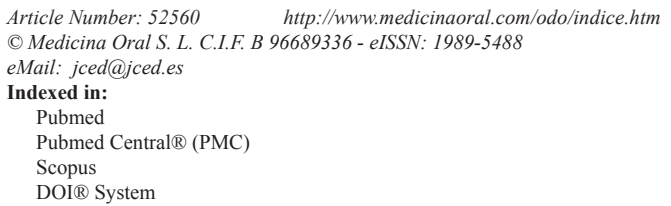

\begin{abstract}
Background: To determine the clinical characteristics of Continuous Neuropathic Orofacial Pain in patients that suffer Persistent Idiopathic Facial Pain (PIFP), Painful Post-Traumatic Trigeminal Neuropathy (PPTTN) or Burning Mouth Syndrome (BMS) and to describe their treatment.

Material and Methods: A retrospective observational study was made, reviewing the clinical history of the patients diagnosed with Continuous Neuropathic Orofacial Pain between 2004 and 2011 at the Orofacial Pain Unit of the Master of Oral Surgery and Implantology of the University of Barcelona and at the Orofacial Pain Unit of the Teknon Medical Center of Barcelona.

Results: The average age of the patients with Continuous Neuropathic Orofacial Pain was 54.5, with a clear female predominance $(86.9 \%, n=20)$. Of all patients, $60.9 \%(n=14)$ were suffering a PIFP, $21.7 \%(n=5)$ had a BMS and $17.4 \%(\mathrm{n}=4)$ were presenting a PPTTN. The pain quality described by the patients with Continuous Neuropathic Orofacial Pain was oppressive $(43.47 \%, \mathrm{n}=10)$, widely represented by patients with PIFP, and burning $(39.13 \%$, $\mathrm{n}=9$ ) being the only quality that described patients with BMS. The treatment carried out with the patients was only pharmacologic. The most used drugs for the treatment of PIFP and PPTTN were clonazepam $(50 \%, \mathrm{n}=9)$ and amitriptyline $(44.44 \%, n=8)$. However, a $55.5 \%(n=10)$ of the patients with PIFP or PPTTN required the association of two or more drugs for a correct pain control. All the patients with BMS responded satisfactorily to clonazepam. Conclusions: Continuous Neuropathic Orofacial Pain is a little known condition among the general population, physicians and dentists. This favors a late diagnosis and inaccurate treatments which entail unnecessary suffering. It is important to inform both the general population and health professionals concerning this painful condition.
\end{abstract}

Key words: Continuous neuropathic orofacial pain, persistent idiopathic facial pain, painful post-traumatic trigeminal neuropathy, burning mouth syndrome, atypical odontalgia. 


\section{Introduction}

Neuropathic pain is one of the most frustrating conditions that challenge dental clinicians because a wrong diagnosis may involve the realization of incorrect treatments. According to the International Association for the Study of Pain, neuropathic pain is initiated or caused by a primary lesion or a nervous system dysfunction (1). Therefore, neuropathic pain represents a structural or functional anomaly in the peripheral or central nervous system while somatic pain is a damage alert system, predominantly (2). There are two main types of orofacial neuropathic pain: episodic neuropathic pain (mostly represented by paroxysmal neuralgias) and continuous neuropathic pain. Continuous neuropathic pain differs from episodic neuropathic pain by presenting periods of high and low intensity without complete remission. The diagnostic key is the absence of a somatic source of pain $(2,3)$. This descriptive retrospective study focuses on patients that suffer Persistent Idiopathic Facial Pain (PIFP), Painful Post-traumatic Trigeminal Neuropathy (PPTTN) or Burning Mouth Syndrome (BMS), all included in the group of Continuous Neuropathic Orofacial Pain.

The International Classification of Headache Disorders of the International Headache Society (IHS) includes PIFP, PPTTN and BMS in the group Painful cranial neuropathies and other facial pains (group 13) (4). Okeson et al. $(2,3,5)$ divided Continuous Neuropathic Orofacial Pain in three types: centrally mediated pain, peripherally mediated pain and metabolite polyneuropathies. These authors, unlike IHS, classify PPTTN (formerly known as Anesthesia Dolorosa) as a peripherally mediated pain because they attribute it to nervous deafferentation and traumatic neuroma $(2,3)$.

Persistent Idiopathic Facial Pain, previously called Atypical Facial Pain, is diagnosed by excluding all other pathologies that may cause facial pain in the affected area. PIFP is described as a persistent facial and/or oral pain, with varying presentations but recurring daily for more than 2 hours per day over more than 3 months, in the absence of clinical neurological deficit (4). It is a chronic form of facial pain that is normally continuous, deep and poorly located, of low to moderate intensity with sporadic episodes of intense pain $(5,6)$. A dental cause has been excluded by appropriate investigations. If this pain is located in a teeth or near a teeth is named Atypical Odontalgia $(2,4,7)$.

Painful post-traumatic trigeminal neuropathy is a deafferentation pain that results from a loss of normal afferent information that reaches the central nervous system (CNS). PPTTN is a traumatic neuralgia, generally due to a traumatic neuroma formation after a surgical procedure or trauma (2). The diagnostic criterion is unilateral facial or oral pain following trauma to the trigeminal nerve, with clinically evident positive (hyperalgesia, allodynia) and/or negative (hypoaesthesia, hypoalgesia) signs of trigeminal nerve dysfunction. Pain is located in the distribution of the same trigeminal nerve and it has to be developed within 3-6 months of the traumatic event (4). Finally, Burning Mouth Syndrome is an intraoral burning or dysaesthetic sensation on the tongue, lips, gingiva and/or oral mucosa, recurring daily for more than 2 hours per day over more than 3 months, without clinically evident causative lesions. Oral mucosa is of normal appearance and clinical examination including sensory testing is normal $(2,4,8,9)$.

The objective of this study is to determine the clinical characteristics of Continuous Neuropathic Orofacial Pain in patients that suffer PIFP, PPTTN or BMS and to describe their treatment.

\section{Material and Methods}

A retrospective observational study was made by means of reviewing the clinical records of patients diagnosed with Continuous Neuropathic Orofacial Pain seen between 2004 and 2011 at the Orofacial Pain Unit of the Master of Oral Surgery and Implantology of University of Barcelona and the Orofacial Pain Unit of Teknon Medical Center of Barcelona. The study design was approved by the Research and Ethics Committees of University.

The patients included were under clinical diagnosis of PIFP, PPTTN and BMS, according to group 13 of the International Classification of Headache Disorders of the International Headache Society. The patients with incomplete protocols were excluded.

The variables collected were divided in three categories: - Patient variables: gender, age at the moment of diagnosis and the presence of systemic disease or psychological/psychiatric disorders.

- Pain variables: clinical diagnosis, quality, intensity, anatomical location, duration, pain aggravators and relievers, the possible trigger, time of evolution to clinical diagnosis and the concomitant symptoms of pain.

- Therapeutic variables: prescribed drug treatment and its side effects.

The patient data and the pain characteristics that were used for the statistical study were registered during the first visit to the Orofacial Pain Units. All the patients were subjected to the same protocolized clinical history. The quality of pain was registered by showing the patients a list of descriptive adjectives: oppressive, electrical, burning, shooting, sharp and throbbing. In order to register the pain intensity, the patients were asked to classify it as low, moderate or intense.

Tables 1, 2 and 3 show the pain characteristics of each patient according to the clinical diagnosis: PIFP, PPTTN or BMS.

Microsoft Access for Windows was used for data collection. A descriptive analysis was performed with the Statistical Package for the Social Sciences for Windows (SPSS v15.0; SPSS Inc. Chicago, IL, USA, University of Barcelona license). 
Table 1. Characteristics of pain in patients with Burning Mouth Syndrome.

\begin{tabular}{|l|c|c|c|c|c|}
\hline & $\mathbf{1}$ & $\mathbf{2}$ & $\mathbf{3}$ & $\mathbf{4}$ & $\mathbf{5}$ \\
\hline Age (years old) & 62 & 43 & 68 & 56 & 70 \\
\hline Gender & Male & Female & Female & Female & Female \\
\hline Quality & Burning & Burning & Burning & Burning & Burning \\
\hline Intensity & $\begin{array}{c}\text { Moderate } \\
\text { Intense }\end{array}$ & Low & Moderate & Moderate & $\begin{array}{c}\text { Low } \\
\text { Moderate }\end{array}$ \\
\hline Affected area & Tongue & Tongue & $\begin{array}{c}\text { Tongue } \\
\text { Palate }\end{array}$ & $\begin{array}{c}\text { Tongue } \\
\text { Gingiva }\end{array}$ & $\begin{array}{c}\text { Longue } \\
\text { Oral Mucosa }\end{array}$ \\
\hline Duration & Continuous & Continuous & $\begin{array}{c}\text { Fluctuating } \\
\text { (during the day) }\end{array}$ & Continuous & $\begin{array}{c}\text { Fluctuating } \\
\text { (during the day) }\end{array}$ \\
\hline Trigger & Unknown & Unknown & Unknown & Unknown & Unknown \\
\hline
\end{tabular}

Table 2. Characteristics of pain in patients with Persistent Idiophatic Facial Pain.

\begin{tabular}{|c|c|c|c|c|c|c|c|}
\hline & $\begin{array}{c}\text { Age } \\
\text { (years old) }\end{array}$ & Gender & Quality & Intensity & Area affected & Duration & Trigger \\
\hline 1 & 58 & Female & Opressive & Low & Superior molars & Continuous & $\begin{array}{l}\text { Dental implant } \\
\text { surgery }\end{array}$ \\
\hline 2 & 37 & Female & Opressive & Moderate & Superior molars & Continuous & Unknown \\
\hline 3 & 53 & Female & $\begin{array}{l}\text { Opressive } \\
\text { Throbbing }\end{array}$ & $\begin{array}{l}\text { Moderate } \\
\text { Intense }\end{array}$ & $\begin{array}{l}\text { Superior premo- } \\
\text { lars and molars }\end{array}$ & Continuous & $\begin{array}{l}\text { Placement of fixed } \\
\text { prostheses }\end{array}$ \\
\hline 4 & 57 & Female & $\begin{array}{l}\text { Electrical } \\
\text { Sharp }\end{array}$ & Moderate & Intermenton area & $\begin{array}{c}\text { Fluctuating } \\
\text { (during the day) }\end{array}$ & $\begin{array}{l}\text { Dental implant } \\
\text { surgery }\end{array}$ \\
\hline 5 & 54 & Female & $\begin{array}{l}\text { Burning } \\
\text { Electrical }\end{array}$ & Moderate & Premaxilla & Continuous & Lip hair waxing \\
\hline 6 & 34 & Male & Electrical & $\begin{array}{c}\text { Low } \\
\text { Moderate }\end{array}$ & Infraorbital aera & $\begin{array}{c}\text { Fluctuating } \\
\text { (during the day) }\end{array}$ & Unknown \\
\hline 7 & 50 & Female & $\begin{array}{l}\text { Opressive } \\
\text { Burning }\end{array}$ & Moderate & Infraorbital area & Continuous & Depression \\
\hline 8 & 50 & Female & $\begin{array}{l}\text { Opressive } \\
\text { Burning }\end{array}$ & Moderate & Superior molars & $\begin{array}{c}\text { Fluctuating } \\
\text { (during the day) }\end{array}$ & Extraction of 2.8 \\
\hline 9 & 47 & Male & Electrical & $\begin{array}{c}\text { Low } \\
\text { Moderate } \\
\text { Intense }\end{array}$ & Superior molars & $\begin{array}{c}\text { Fluctuating } \\
\text { (during the day) }\end{array}$ & Extraction of 1.6 \\
\hline 10 & 53 & Female & Opressive & Moderate & Infraorbital area & Continuous & Unknown \\
\hline 11 & 67 & Female & $\begin{array}{l}\text { Opressive } \\
\text { Sharp }\end{array}$ & Intense & Superior molars & Continuous & Extraction of 1.8 \\
\hline 12 & 58 & Female & Opressive & Moderate & Superior molars & $\begin{array}{c}\text { Fluctuating } \\
\text { (during the day) }\end{array}$ & Extraction of 2.8 \\
\hline 13 & 52 & Female & Opressive & $\begin{array}{l}\text { Moderate } \\
\text { Intense }\end{array}$ & Premaxilla & $\begin{array}{c}\text { Fluctuating } \\
\text { (during the day) }\end{array}$ & $\begin{array}{l}\text { Dental implant } \\
\text { surgery }\end{array}$ \\
\hline 14 & 51 & Female & Throbbing & Moderate & Infraorbital area & $\begin{array}{c}\text { Fluctuating } \\
\text { (during the day) }\end{array}$ & Unknown \\
\hline
\end{tabular}


Table 3. Characteristics of pain in patients with Anesthesia Dolorosa.

\begin{tabular}{|c|c|c|c|c|}
\hline & 1 & 2 & 3 & 4 \\
\hline $\begin{array}{l}\text { Age } \\
\text { (years old) }\end{array}$ & 55 & 67 & 60 & 48 \\
\hline Gender & Female & Female & Female & Female \\
\hline Quality & $\begin{array}{c}\text { Sharp } \\
\text { Electrical }\end{array}$ & $\begin{array}{l}\text { Electrical } \\
\text { Sharp }\end{array}$ & Burning & $\begin{array}{l}\text { Opressive } \\
\text { Shooting }\end{array}$ \\
\hline Intensity & Moderate & Moderate & $\begin{array}{c}\text { Low } \\
\text { Moderate }\end{array}$ & $\begin{array}{l}\text { Moderate } \\
\text { Intensive }\end{array}$ \\
\hline Area affected & $\begin{array}{c}\text { Intermenton } \\
\text { zone }\end{array}$ & $\begin{array}{l}\text { Inferior } \\
\text { lip }\end{array}$ & $\begin{array}{c}\text { Infraorbital } \\
\text { area }\end{array}$ & $\begin{array}{l}\text { Lip and inferior } \\
\text { premolars }\end{array}$ \\
\hline Duration & Continuous & Continuous & Continuous & Continuous \\
\hline Trigger & $\begin{array}{l}\text { Dental implant } \\
\text { surgery }\end{array}$ & Tumoral exeresis & $\begin{array}{c}\text { Extraction of } \\
\text { premolars }\end{array}$ & Extraction of 3.8 \\
\hline $\begin{array}{l}\text { Sensory } \\
\text { alterations }\end{array}$ & $\begin{array}{l}\text { Hyperesthesia } \\
\text { on gingiva }\end{array}$ & $\begin{array}{l}\text { Hyperesthesia of } \\
\text { the inferior lip }\end{array}$ & $\begin{array}{c}\text { Parestesia on } \\
\text { infraorbital } \\
\text { area }\end{array}$ & $\begin{array}{c}\text { Parestesia of the } \\
\text { inferior lip }\end{array}$ \\
\hline
\end{tabular}

\section{Results}

The study sample consisted of 23 patients with Continuous Neuropathic Orofacial Pain, with a clear female predominance $(86.9 \%, \mathrm{n}=20)$. The average age of patients was 54.5 (range 34-70). Of all patients, 60.9\% $(n=14)$ were suffering a PIFP, $21.7 \%(n=5)$ had a BMS and $17.4 \%(n=4)$ were presenting a PPTTN. The mean evolution time, namely the period between onsets of the symptoms and diagnosis, was 28.1 months (ranging from 0.5 to 96 ).

PIFP were located at the maxilla in $64.3 \%(n=9)$ of cases, at the infraorbital area in $28.6 \%(n=4)$ and one case $(7.1 \%, \mathrm{n}=1)$ at the intermenton (chin) zone. The location of PPTTN was $50 \%(n=2)$ on the inferior lip, and $25 \%$ $(n=1)$ on the intermenton zone and the infraorbital zone. All the BMS were located in the tongue $(100 \%, n=5)$, although three patients also referred having burning pain in the palate, oral mucosa and lips.

The pain quality described by the patients with Continuous Neuropathic Orofacial Pain was $(n=23)$ : oppressive $(43.47 \%, n=10)$, widely represented by patients with PIFP, burning $(39.13 \%, n=9)$, being the only quality that described patients with BMS, electrical $(26.08 \%, n=6)$, sharp $(17.39 \%, n=4)$, throbbing $(8.69 \%, n=2)$ and 1 patient with PPTTN referred shooting pain $(4.34 \%, n=1)$. The $39.13 \%(n=9)$ of cases reported two or more types of pain quality.

The most prevalent pain intensity was moderate $(86.9 \%$, $\mathrm{n}=20)$, followed by low $(26.08 \%, \mathrm{n}=6)$ and severe intensity $(26.08 \%, n=6)$. Variations of pain intensity were described by $34.78 \%(n=8)$ of participants.

Stress increased the pain intensity for $34.8 \%(n=8)$ of cases and $43.5 \%(n=10)$ of the patients presented other systemic diseases and psychiatric/psychological disorders related or not to the chronic pain.

All the patients with PPTTN $(n=4)$ reported that their pain was triggered by a surgical procedure on the affected nervous zone and all the patients presented sensory alterations on the affected area (hyperesthesia, dysesthesia or paresthesia). The $71.43 \%(n=10)$ of patients that suffered a PIFP reported a pain trigger, for instance a surgical procedure, depression or lip hair waxing. No patients with PIFP presented sensibility alterations on the painful area. The patients with BMS did not report any pain triggering.

The treatment carried out with the patients was only pharmacologic. We divided the patients into two therapeutic groups. The first group describes the treatments performed for patients with PIFP and PPTTN. Patients with BMS comprised the second group.

PIFP and PPTTN $(n=18)$ patients may often respond similarly to the same drug treatment, interindividual differences being essential. Association of two or more drugs for the correct pain control was required for $55.5 \%$ $(n=10)$ of these patients. The $50 \%(n=9)$ of cases were treated with clonazepam, 44.44\% $(\mathrm{n}=8)$ received amitriptyline and $33.33 \%(n=6)$ duloxetine. Besides, venlafaxine $(n=1,5.55 \%)$, nortriptyline $(n=1,5.55 \%)$, pregabalin $(n=1,5.55 \%)$ and gabapentine $(n=1,5.55 \%)$ were used. The drug most associated with the other ones was clonazepam. The drug of choice that we first used in all the patients of this group was amitriptyline. The most described side effects were drowsiness $(n=2)$, fatigue $(n=3)$, xerostomia $(n=4)$, cardiovascular $(n=2)$ and sensory alterations $(n=2)$, among others.

All the patients with BMS $(n=5)$ responded satisfacto- 
rily to treatment with clonazepam, at doses of $1-1.5 \mathrm{mg} /$ day. The described side effects were somnolence $(n=2)$, fatigue $(\mathrm{n}=1)$ and aggressiveness $(\mathrm{n}=1)$.

\section{Discussion}

To date, the prevalence of PIFP in the general population is still unknown. According to this study, a higher prevalence of PIFP has been found among women. The highest prevalence of cases reported by literature is around the fourth decade of life, unlike in our sample that appears in the fifties $(3,7,10)$. Although all ages may be affected by this painful condition, a case of impairment in childhood has not yet been described in literature. In our study, the youngest patient was 34 years old (7). Atypical Odontalgia presents as tooth pain or pain in a site where a tooth was extracted, in the absence of clinical and radiographic evidence of tooth pathology (11-13). PIFP has been described to occur in $3 \%$ to $6 \%$ of patients who undergo endodontic treatment $(11,14)$. However, any patients in our study referred a previous endodontic treatment as a pain trigger. The referred causes were an oral surgery procedure (tooth extraction, periapical surgery and dental implant surgery) and other non-dental related causes such as history of depression, sinusitis and lip hair waxing. Although PIFP has been very little related to dental implant placement in the whole literature, we present four cases (15).

According to this work, some studies report that molars and premolars are the most frequently involved teeth and that the maxilla is more often affected than the mandible $(7,16,17)$.

Regarding to PPTTN, it has not been described to have a gender tendency. All the patients have sensory alterations (hyperesthesia, dysesthesia or paresthesia) and relate that the start of pain was a surgical procedure like dental implant surgery $(3,4,18)$. Renton and Yilmaz (12) reported a sample of 90 patients having iatrogenic lesions of inferior alveolar nerve: $60 \%$ appeared after third molar extraction, $19 \%$ after inferior alveolar block anaesthesia, $18 \%$ after dental implant placement and 8\% were associated with endodontic treatment. These patients described allodynia, paresthesia, dysesthesia and hyperesthesia (2-4).

According to the available literature, tricyclic antidepressants (TCAs) seem to be the most effective medication for the treatment of neuropathic chronic orofacial pain (7,19-21). TCAs such as amitriptyline inhibit the recapture of serotonin and norepinephrine, neurotransmitters which are known to be present in CNS sites involved in pain inhibition (22). Therefore, it is suggested that TCAs could mediate therapeutic effects by increasing the activity of CNS pain inhibitory mechanism. Additionally, amitriptyline has affinity for muscarinic, histaminic and $\beta$-adrenergic receptors (14). Maybe this lower affinity is the responsible of its therapeutic effect. The amitriptyli- ne, unlike other TCAs used in the treatment of chronic neuropathic pain (such as nortriptyline and desipramine), presents a high affinity for the above mentioned receptors (23). Other studies show that $\beta$-blockers and some anticonvulsants as clonazepam, gabapentine and baclofen seem to be fairly effective in the treatment of continuous neuropathic orofacial pain $(15,19,24)$. Topical medications such as capsaicin, at a concentration of $0.025 \%$, also give good results in certain patients with this disorder $(2,15)$.

In agreement with these findings, the most used drugs in our patients diagnosed with PPTTN and PFIP were clonazepam and amitriptyline. The drug of choice that we first used in all these patients was amitriptyline. However, in a third of patients with PPTTN and PIFP, we had to prescribe two or more drugs to achieve an adequate pain control.

BMS is a painful intraoral sensation characterized by the burning sensation of the tongue, lips, gingiva and/or oral mucosa (2). All the patients of our study were females $(n=5)$ and described a burning pain on the tongue; besides, some of them referred pain on the lips, gingiva and palate. The literature shows that the age of presentation of BMS varies from 50 to 70 years old, being rare before the third decade $(2,25)$. Typically, it initiates around or after the menopausal period. Our group had an average age of 59.8 years old; the youngest patient was 43 years old. The intensity of pain ranges from low to intense, appearing while waking up or later during the day. BMS does not cause incapacity and it usually has a sudden onset $(2,8)$. The appearance of the oral soft tissue is normal or reveals few clinical abnormalities (2). From our patients, only one had an oral lichen planus on the painful area. The diagnostic criteria that we used are described in figure 1.

Clonazepam is the most commonly reported drug in literature to treat BMS $(2,26,27)$. This anticonvulsant benzodiazepine is often used with an initial dose of 0.25 $\mathrm{mg}$ /day and after, the dose increases to $0.25 \mathrm{mg} /$ week to achieve adequate pain control, with a maximum of $3 \mathrm{mg} /$ day $(2,26)$. Heckmann et al. (27) performed a randomized placebo-controlled clinical trial on clonazepam for the treatment of BMS and proved its therapeutic efficacy. Other drugs, such as TCAs (excluding amitriptyline because it induces hyposialia), gabapentine, paroxetine and chlordiazepoxide have been proposed for the treatment of BMS but with lower efficacy than clonazepam (27-29). In our study, pain was correctly controlled in all patients with BMS by means of clonazepam.

A recent study by Yang and Huang (30) proposes the use of a soft laser for the control of pain in BMS. They recommend the application of 1 to 7 sessions of laser. They describe a decreasing in pain of $47.6 \%$. A similar result was reached in another study on the use of soft lasers in the treatment of pain in BMS (31). 


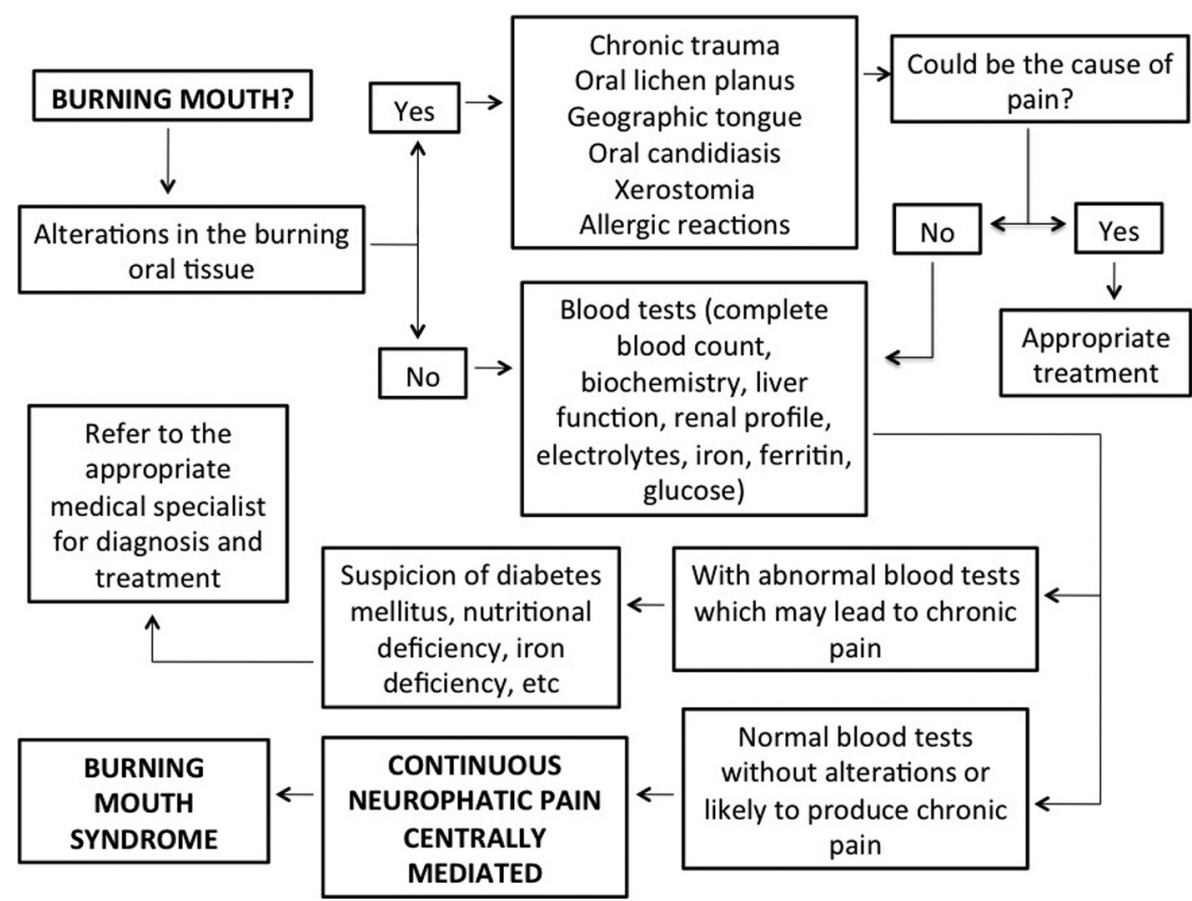

Fig. 1. Proposal of criteria to consider in establishing the diagnosis of Burning Mouth Syndrome.

\section{Conclusions}

Continuous neuropathic orofacial pain is a little known condition among the general population, physicians and dentists. Unfortunately, this favors a late diagnosis and an inaccurate treatment which entails unnecessary suffering for the patient. It is important to inform the general population and health professionals concerning this painful condition.

\section{References}

1. Merskey H. Clarifying definition of neuropathic pain. Pain. 2002;96:408-9.

2. Okeson JP. The classification of orofacial pains. Oral Maxillofac Surg Clin North Am. 2008;20:133-44.

3. Okeson JP. Nonodontogenic toothache. Tex Dent J. 2000;117:6474.

4. Headache Classification Committee of the International Headache Society (HIS). The International Classification of Headache Disorders, 3rd edition (beta version). Cephalalgia. 2013;33:629-808.

5. Okeson JP, de Leeuw R. Differential diagnosis of temporomandibular disorders and other orofacial pain disorders. Dent Clin North Am. 2011;55:105-20.

6. Vickers ER, Cousins MJ, Walter S, Chisholm K. Analysis of 50 patients with atypical odontalgia: a preliminary report on pharmacological procedures for diagnosis and treatment. Oral Surg Oral Med Oral Pathol Endod. 1998;85:24-32.

7. Melis M, Lobo SL, Ceneviz C, Zawawi K, Al-Badawi E, Maloney $\mathrm{G}$, et al. Atypical odontalgia: a review of the literature. Headache. 2003;43:1060-74.

8. Grushka M, Epstein JB, Gorsky M. Burning mouth syndrome. Am Fam Physician. 2002;4:615-20.

9. Zakrzewska JM, Forssell H, Glenny AM. Interventions for the treatment of burning mouth syndrome. Cochrane Database Syst Rev. 2005; $1:$ CD002779.

10. Okeson JP. Non-odontogenic toothache. Northwest Dent. 2000;79:37-44.

11. Marbach JJ, Hulbrock J, Hohn C, Segal AG. Incidence of phantom tooth pain: an atypical facial neuralgia. Oral Surg Oral Med Oral Pathol. 1982;53:190-3.

12. Renton T, Yilmaz Z. Profiling of patients presenting with posttraumatic neuropathy of the trigeminal nerve. J Orofac Pain. 2011;25:33344.

13. Woda A, Pionchon P. A unified concept of idiopathic orofacial pain: clinical features. J Orofac Pain. 1999;13:172-95.

14. Pertes RA, Balley DR, Milone AS. Atypical odontalgia -- a nondental toothache. J N J Dent Assoc. 1995;66:29-31.

15. Queral-Godoy E, Vazquez-Delgado E, Okeson JP, Gay-Escoda C. Persistent idiopathic facial pain following dental implant placement: a case report. Int J Oral Maxillofac Implants. 2006;21:136-40.

16. Klausner JJ. Epidemiology of chronic facial pain: diagnostic usefulness in patient care. J Am Dent Assoc. 1994;125:1604-11.

17. Okeson JP, Falace DA. Nonodontogenic toothache. Dent Clin North Am. 1997;41:367-83.

18. Al-Sabbagh M, Okeson JP, Bertoli E, Medynski DC, Khalaf MW. Persistent pain and neurosensory disturbance after dental implant surgery: prevention and treatment. Dent Clin North Am. 2015;59:14356.

19. Al-Sabbagh M, Okeson JP, Khalaf MW, Bhavsar I. Persistent pain and neurosensory disturbance after dental implant surgery: pathophysiology, etiology, and diagnosis. Dent Clin North Am. 2015;59:13142.

20. Chong MS, Bajwa ZH. Diagnosis and treatment of neuropathic pain. J Pain Symptom Manage. 2003;25:s4-s11.

21. Fields HL. Pain modulation: Expectation, opioid analgesia and virtual pain. Prog Brain Res. 2000;122:245-53.

22. Finnerup NB, Sindrup SH, Jensen TS. The evidence for pharmacological treatment of neuropathic pain. Pain. 2010;150:573-81.

23. Torrente Castells E, Vázquez Delgado E, Gay Escoda C. Use of amitriptyline for the treatment of chronic tension-type headache. Review of the literature. Med Oral Patol Oral Cir Bucal. 2008;13:e56772.

24. Peters S, Goldthorpe J, McElroy C, King E, Javidi H, Tickle M, et al. Managing chronic orofacial pain: a qualitative study of patients', doctors', and dentists' experiences. Br J Health Psychol. 2015;20:777-91. 25. Coculescu EC, Tovaru S, Coculescu BI. Epidemiological and etiological aspects of burning mouth syndrome. J Med Life. 2014;7:305-9. 
26. Mínguez-Serra MP, Salort-Llorca C, Silvestre-Donat FJ. Pharmacological treatment of burning mouth syndrome: a review and update. Med Oral Patol Oral Cir Bucal. 2007;12:299-304.

27. Heckmann SM, Kirchner E, Grushka M, Wichmann MG, Hummel $\mathrm{T}$. A double-blind study on clonazepam in patients with burning mouth syndrome. Laryngoscope. 2012;122:813-6.

28. List T, Axelsson S, Leijon G. Pharmacologic interventions in the treatment of temporomandibular disorders, atypical facial pain, and burning mouth syndrome: a qualitative systematic review. J Orofac Pain. 2003;17:301-10.

29. Coculescu EC, Radu A, Coculescu BI. Burning mouth syndrome: a review on diagnosis and treatement. J Med Life. 2014;7:512-5.

30. Yang HW, Huang YF. Treatment of burning mouth syndrome with a low-level energy diode laser. Photomed Laser Surg. 2011;29:123-5. 31. Dos Santos LdeF, Carvalho Ade A, Leao JC, Cruz Perez DE, Castro JF. Effect of low-level laser therapy in the treatment of burning mouth syndrome: a case series. Photomed Laser Surg. 2011;29:793-6.

Acknowledgements

This study was conducted by the consolidated Research Group in "Dental and Maxillofacial Pathology and Treatment" of the Bellvitge Institute for Biomedical Research (IDIBELL). 